\title{
Prostatic urethral angle might be a predictor of treatment efficacy of $\alpha$-blockers in men with lower urinary tract symptoms
}

This article was published in the following Dove Press journal:

Drug Design, Development and Therapy

I5 July 2014

Number of times this article has been viewed

\section{Chen-Pang Hou' \\ Chien-Lun Chen' \\ Yu-Hsiang Lin' \\ Yu-Lun Tsai' \\ Phei-Lang Chang' \\ Horng-Heng Juang ${ }^{2}$ \\ Ke-Hung Tsui'}

'Department of Urology, Chang Gung Memorial Hospital, College of Medicine, Chang Gung University, ${ }^{2}$ Department of Anatomy, College of Medicine, Chang Gung University, Taoyuan, Taiwan, Republic of China
Correspondence: Ke-Hung Tsui

Department of Urology, Chang Gung Memorial Hospital, Chang Gung

University, 5 Fu-Shing Street, Kwei-Shan, Taoyuan 333, Taiwan, Republic of China Tel $+8863328 \quad 1200$ ext 2137

Fax +886321I 8II2

Email khtsui@yahoo.com
Purpose: We investigated the association of the prostatic urethral angle (PUA) with peak urinary flow rate $\left(\mathrm{Q}_{\max }\right)$ and the severity of lower urinary tract symptoms (LUTS) on the aging male. We also evaluated the effect of the PUA on the treatment efficacy of tamsulosin on men with LUTS.

Materials and methods: The records were obtained from a prospective database for first-visit male patients with LUTS in the outpatient department of our institution. These patients underwent a detailed physical examination and taking of medical history. A transrectal ultrasound was performed on these patients. The prostate size, length of intravesical prostatic protrusion (IPP), PUA, and International Prostate Symptom Score (IPSS) of the patients were evaluated. Uroflowmetry and a bladder scan for residual urine were also performed on every patient. Tamsulosin $0.2 \mathrm{mg}$ per day was prescribed. The IPSS and uroflowmetry were reevaluated after they had received treatment for 3 months.

Results: A total of 178 patients were included, and 149 of them completed this cohort study. The mean PUA was $48.32^{\circ} \pm 13.74^{\circ}$. The mean prostate volume was $39.19 \pm 20.87 \mathrm{~mL}$, and the mean IPP was $5.67 \pm 7.85 \mathrm{~mm}$. On multivariate linear regression analysis, the PUA was independently associated with the IPSS $(P<0.001), \mathrm{Q}_{\max }(P=0.004)$, post-treatment IPSS change $(P=0.032)$, and post-treatment $\mathrm{Q}_{\max }$ change $(P<0.001)$. However, the prostate volume and IPP were not associated with these clinical items.

Conclusion: The PUA is significantly associated with $\mathrm{Q}_{\max }$ and IPSS in men with LUTS. The PUA is also inversely correlated with changes in $\mathrm{Q}_{\max }$ and IPSS after tamsulosin treatment. Namely, the PUA might be a predictor for the treatment efficacy of $\alpha$-blockers in aging men with LUTS.

Keywords: prostatic urethral, prostate, International Prostate Symptom Score, benign prostatic hyperplasia

\section{Introduction}

Benign prostatic hyperplasia (BPH) is a major cause of lower urinary tract symptoms (LUTS) in the aging male. It affects about 210 million males globally. ${ }^{1}$ Although $\mathrm{BPH}$ has been considered to be the most significant risk factor for LUTS, several studies have reported that prostate size does not correlate with the severity of the symptoms. ${ }^{2,3}$ Therefore, there are some other prostatic anatomic factors that have been considered as potential factors affecting clinical symptoms, such as the transitional zone index and intravesical prostatic protrusion (IPP). ${ }^{4-6}$ Recently, the prostatic urethral angle (PUA) has been regarded as an important influencing factor in male LUTS. $^{7}$ The prostatic urethra is a bent tube. During micturition, the kinetic energy of the voiding urine decreases due to the PUA. The greater the angle, the more the 
kinetic energy decreases. ${ }^{8}$ Cho et al used a mathematical simulation to demonstrate the relationship between the urinary flow rate and the PUA: ${ }^{7}$

$$
\mathrm{Q}=\frac{\pi \mathrm{d}^{2}}{4} \sqrt{\frac{2 \mathrm{p}}{\mathrm{e}\left(1+2.22 \times 10^{-3} \theta+4.04 \times 10^{-6} \theta^{2.762}\right)}}
$$

In the equation, $\mathrm{Q}$ represents the urine flow rate at the end of the prostate urethra, $d$ represents the prostatic urethra diameter, $\mathrm{p}$ represents the vesical pressure, and $\theta$ represents the PUA. We find that the greater the angle of $\theta$, the lower $\mathrm{Q}$ is. In other words, the urinary flow rate is inversely associated with the PUA.

Although the relationship between PUA and LUTS as well as the urinary flow rates has been discussed in the literature, no study has mentioned the relationship between the PUA and the treatment effect of $\alpha$-blockers on LUTS. To demonstrate the correlation between the effect of $\alpha$-blocker treatment and the PUA, we used the Navier-Stokes hydromechanics equation ${ }^{9}$ to modify the formula suggested by Cho et al:

$$
\begin{aligned}
\Delta \mathrm{Q}= & \pi / 4\left(\mathrm{D} 1^{2}-\mathrm{D} 0^{2}\right) \\
& \times \sqrt{\frac{2 \mathrm{p}}{\mathrm{e}\left(1+2.22 \times 10^{-3} \theta+4.04 \times 10^{-6} \theta^{2.762}\right)}}
\end{aligned}
$$

In this mathematical simulation, $\Delta \mathrm{Q}$ represents the flow rate increase after $\alpha$-blocker treatment. D0 and D1 represent the urethra diameter before and after treatment, respectively. In this equation, $\Delta \mathrm{Q}$ will decrease if $\theta$ increases. In other words, we can hypothesize that improvement of voiding velocity after treatment is also inversely associated with the PUA. However, this is only a hypothesis, and it needs more clinical observation in order to confirm it. The purpose of this study was to investigate the impact of the PUA on urinary flow rate and LUTS. In addition, we set out to test our hypothesis that PUA has a negative impact on the treatment efficacy of $\alpha$-blockers in BPH patients.

\section{Materials and methods}

The present study was approved by the institutional review board at Chang-Gung Memorial Hospital. From October 2012 to June 2013, we obtained records from a prospective database for first-visit male patients with LUT syndrome in the outpatient department of our institution. These patients underwent a detailed physical examination and taking of medical history. They were excluded if they had such comorbidities as any malignant disease, any evidence of a neurologic disorder that could affect voiding function, or uncontrolled diabetes mellitus. Furthermore, those who presented with an indwelling urinary catheter, had a history of prostate surgery, were taking a $5 \alpha$-reductase inhibitor, or had dementia or any disability interfering with verbal communication were excluded. A total of 178 patients were included in the final study cohort.

Transrectal ultrasonography (TRUS) was performed on these patients by a single urologist using a single ultrasound machine (Aloka SSD-A6; Hitachi, Tokyo, Japan) with a 7.5 $\mathrm{MHz}$ biplanar transrectal probe. The size of the prostate was measured using the ellipse formula (length $\times$ width $\times$ height $\times 0.52$ ). The PUA was defined as the angle formed by the proximal prostate urethra and distal prostate urethra, as suggested by Cho et al. ${ }^{7}$ An illustration is shown in Figure 1A. The IPP was measured from the tip of the protruding prostate into the bladder to the bladder circumference at the prostate base in the sagittal plane, as suggested by Nose et al. ${ }^{10}$ An illustration is shown in Figure $1 \mathrm{~B}$.

The International Prostate Symptom Score (IPSS) ${ }^{11}$ of the patients was also recorded. Uroflowmetry and a bladder scan for residual urine were performed on every patient before treatment. Tamsulosin $0.2 \mathrm{mg}$ per day was prescribed for all patients. After completion of the 3-month treatment period, the IPSS, uroflowmetry, and bladder scan for residual urine were repeated. Data were analyzed using Pearson's correlation coefficient. Multivariate linear regression analysis was performed to analyze the independent association of the patients' parameters with the peak flow rate $\left(\mathrm{Q}_{\max }\right)$, IPSS, and the treatment efficacy of tamsulosin. We used SPSS 15.0 (SPSS Inc., Chicago, IL, USA) for statistical analysis. All statistical tests were conducted with a significance level of 0.05 .

\section{Results}

Patients' clinical characteristics before and after the treatment are summarized in Table 1. A total of 178 patients were included in our study. The mean age of the patients was $66.16 \pm 9.54$ years. The mean total prostate volume was $39.19 \pm 20.87 \mathrm{~mL}$, and the mean PUA was $48.32^{\circ} \pm 13.74^{\circ}$. The mean IPSS, mean $\mathrm{Q}_{\max }$, mean voiding volume, and mean postvoiding residual volume were 17.89 $\pm 4.66,7.36 \pm 2.66 \mathrm{~mL} / \mathrm{second}, 218.44 \pm 64.78 \mathrm{~mL}$, and $33.11 \pm 36.26 \mathrm{~mL}$, respectively. During the 3-month observation period, seven patients were lost to follow-up. Twentytwo patients asked to change their treatment policy because of the poor treatment efficacy of tamsulosin. Twelve of them 

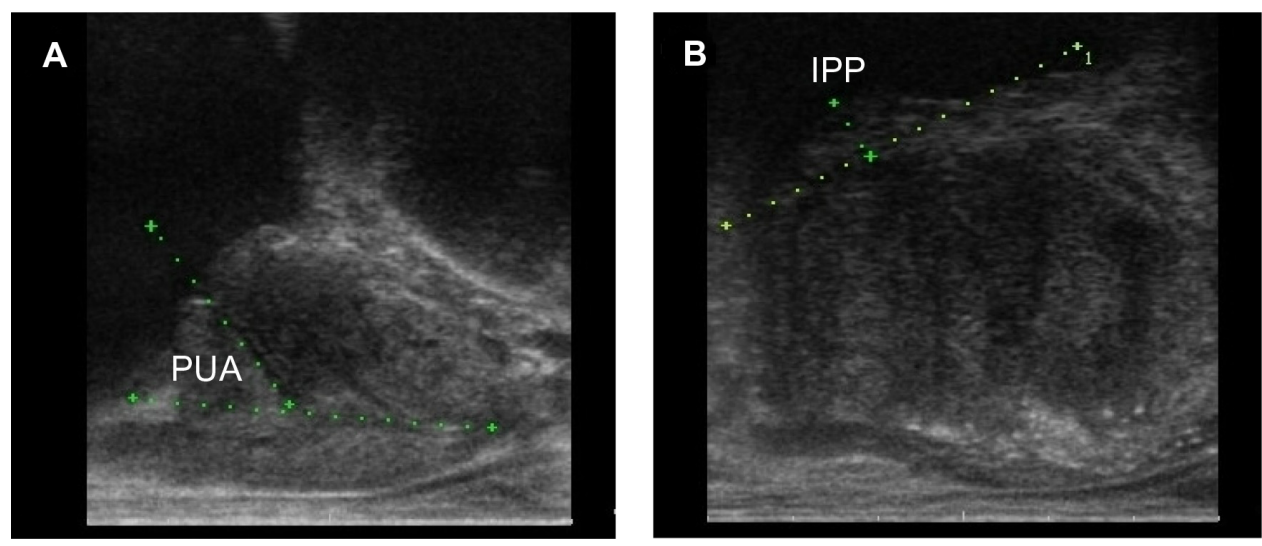

Figure I Ultrasound image used for measurement of PUA and IPP.

Notes: (A) Ultrasound image used for measurement of PUA, which was defined as the angle formed by the proximal prostate urethra and distal prostate urethra. (B) Ultrasound image used for measurement of IPP, which was defined as the length measured from the tip of the protruding prostate into the bladder, to the bladder circumference at the prostate base.

Abbreviations: IPP, intravesical prostate protrusion; PUA, prostatic urethral angle.

asked to increase the dose or change medication, while ten received transurethral resection of the prostate (TUR-P). Therefore, a total of 149 patients completed this cohort study. As shown in Table 1, the IPSS of the 149 patients improved significantly after treatment with tamsulosin for 3 months $(P<0.001)$, whether regarding total scores, voiding symptom scores, or storage symptom scores. The $\mathrm{Q}_{\max }$ and the voiding volume of the patients improved as well $(P<0.001)$. However, there was no remarkable change in the measure of postvoiding residual urine $(33.11 \pm 36.26 \mathrm{~mL}$ versus $28.87 \pm 30.81 \mathrm{~mL}, P=0.287$ ).

Table 2 reveals the relationship between IPSS and the independent prostatic parameters. Using multivariate linear regression models, we found that the PUA had an extremely strong correlation with IPSS, whether regarding total scores $(P<0.001)$, voiding symptom scores $(P<0.001)$, or storage symptom scores $(P=0.024)$. Although total prostate volume had no remarkable correlation with total IPSS $(P=0.088)$ or storage symptom scores $(P=0.348)$, it had a slightly significant association with voiding symptom scores $(P=0.049)$. However, other parameters - age, body mass index (BMI), and IPP - had no correlation with IPSS. Table 3 reveals the relationship between $\mathrm{Q}_{\max }$ and the independent prostatic parameters. We found there was a correlation between both PUA ( $P=0.004)$ and age $(P=0.042)$, while other parameters showed none.

Table I Patient characteristics

\begin{tabular}{|c|c|c|c|}
\hline \multirow[t]{2}{*}{ Characteristic } & Before treatment $(n=\mid 78)$ & After treatment $(n=\mid 49)$ & $P$-value \\
\hline & \multicolumn{2}{|l|}{ Mean \pm SD (range) } & \\
\hline Age, years & $66.16 \pm 9.54(45-88)$ & & \\
\hline $\mathrm{BMI}$ & $24.99 \pm 3.26(42.42-24.90)$ & & \\
\hline \multicolumn{4}{|l|}{ TRUS } \\
\hline TPV, mL & $39.19 \pm 20.87(12.42-132.20)$ & & \\
\hline IPP, mm & $5.67 \pm 7.85(0-31)$ & & \\
\hline $\mathrm{PUA}^{\circ}$ & $48.32 \pm 13.74(24-87)$ & & \\
\hline \multicolumn{4}{|l|}{ IPSS } \\
\hline Total & $17.89 \pm 4.66$ (9-29) & 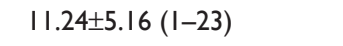 & $<0.00 I^{*}$ \\
\hline Voiding symptoms & $10.09 \pm 3.93(4-19)$ & $6.00 \pm 4.4 \mid(0-17)$ & $<0.001 *$ \\
\hline Storage symptoms & $7.80 \pm 2.22(3-13)$ & $5.24 \pm 2.41(0-12)$ & $<0.00 I^{*}$ \\
\hline \multicolumn{4}{|l|}{ Uroflowmetry } \\
\hline $\mathrm{Q}_{\max }, \mathrm{mL} / \mathrm{second}$ & $7.36 \pm 2.66(2-16)$ & $10.55 \pm 3.32(4-21)$ & $<0.00 I^{*}$ \\
\hline Voiding volume, $\mathrm{mL}$ & $218.44 \pm 64.78(101-453)$ & $290.38 \pm 87.61(93-550)$ & $<0.00 I^{*}$ \\
\hline Postvoiding residual volume, $\mathrm{mL}$ & $33 . I I \pm 36.26(0-22 I)$ & $28.87 \pm 30.81(0-167)$ & 0.287 \\
\hline
\end{tabular}

Note: *Paired t-test.

Abbreviations: SD, standard deviation; BMI, body mass index; IPSS, International Prostate Symptom Score; $Q_{\max }$, peak flow rate; TRUS, transrectal ultrasonography; TPV, total prostate volume; IPP, intravesical prostate protrusion; PUA, prostatic urethral angle. 
Table 2 Relationship between IPSS and prostatic parameters

\begin{tabular}{|c|c|c|c|c|c|c|}
\hline \multirow[t]{2}{*}{ Variable } & \multicolumn{2}{|c|}{ Total score } & \multicolumn{2}{|c|}{$\begin{array}{l}\text { Storage } \\
\text { symptom score }\end{array}$} & \multicolumn{2}{|c|}{$\begin{array}{l}\text { Voiding } \\
\text { symptom score }\end{array}$} \\
\hline & t-ratio & $P$-value & t-ratio & $P$-value & t-ratio & $P$-value \\
\hline & 0.103 & 0.918 & & 0.541 & 0.338 & 0.736 \\
\hline MI & 0.040 & 0.969 & 0.054 & 0.957 & 0.008 & 0.994 \\
\hline TPV & 1.720 & 0.088 & 0.942 & 0.348 & 2.858 & $0.049 *$ \\
\hline IPP & 0.283 & 0.778 & 1.606 & 0.111 & 0.868 & 0.386 \\
\hline PUA & 9.138 & $<0.001 *$ & 2.284 & $0.024^{*}$ & 9.528 & $<0.00 I^{*}$ \\
\hline
\end{tabular}

Note: *Multivariate linear regression analysis.

Abbreviations: IPSS, International Prostate Symptom Score; BMI, body mass index; TPV, total prostate volume; IPP, intravesical prostate protrusion; PUA, prostatic urethral angle.

After treatment with $0.2 \mathrm{mg}$ of tamsulosin once daily for 3 months, most of the patents experienced significant improvement on both IPSS and $\mathrm{Q}_{\max }$. As shown in Table 4, we found that PUA was the only parameter that correlated with IPSS change ( $\triangle$ IPSS, $P=0.032$ ). However, this correlated only with the change of voiding symptom score $(P<0.001)$, and not with the storage symptom score $(P=0.149)$. Table 5 reveals the relationship between $\Delta Q_{\max }$ after tamsulosin treatment and prostatic parameters. We found that PUA was the only parameter that correlated with $\Delta \mathrm{Q}_{\max }$. Pearson's correlation analysis showed that as PUA increased, IPSS also increased, while $\mathrm{Q}_{\max }, \Delta \mathrm{IPSS}$, and $\Delta \mathrm{Q}_{\max }$ decreased, as shown in Figure 2.

\section{Discussion}

Histopathologic BPH begins to develop in men after 40 years of age, and the prevalence becomes greater than $50 \%$ by 60 years of age and as high as $90 \%$ by 85 years of age. ${ }^{12}$ When the prostatic adenoma becomes sufficiently large, the tissue will compress the urethral canal to cause partial or sometimes virtually complete obstruction of the urethra. ${ }^{13}$ This leads to symptoms of weak urinary stream, urinary hesitancy, frequent urination, increased risk of urinary tract infections, and urinary retention. ${ }^{13}$ To evaluate the severity of the symptoms caused by BPH, IPSS have been widely used. ${ }^{14}$ IPSS are composed of seven items (four items for voiding symptoms

Table 3 Relationship between $\mathrm{Q}_{\max }$ and prostatic parameters

\begin{tabular}{lll}
\hline Variable & t-ratio & P-value \\
\hline Age & 2.038 & $0.042^{*}$ \\
BMI & 0.012 & 0.989 \\
TPV & 1.690 & 0.093 \\
IPP & 0.059 & 0.952 \\
PUA & 2.946 & $0.004^{*}$ \\
\hline
\end{tabular}

Note: *Multivariate linear regression analysis.

Abbreviations: $\mathrm{Q}_{\max }$, peak flow rate; $\mathrm{BMI}$, body mass index; TPV, total prostate volume; IPP, intravesical prostate protrusion; PUA, prostatic urethral angle.
Table 4 Relationship between IPSS change and prostatic parameters after tamsulosin treatment

\begin{tabular}{|c|c|c|c|c|c|c|}
\hline \multirow[t]{2}{*}{ Variable } & \multicolumn{2}{|c|}{$\Delta$ total score } & \multicolumn{2}{|c|}{$\begin{array}{l}\Delta \text { storage } \\
\text { symptom score }\end{array}$} & \multicolumn{2}{|c|}{$\begin{array}{l}\Delta \text { voiding } \\
\text { symptom score }\end{array}$} \\
\hline & t-ratio & $P$-value & t-ratio & $P$-value & t-ratio & $P$-value \\
\hline & & $0.54 I$ & 0.680 & 0.497 & 0.333 & 0.739 \\
\hline BMI & 1.505 & 0.134 & 0.941 & 0.342 & 0.343 & 0.732 \\
\hline TPV & 0.253 & 0.800 & $0.34 I$ & 0.734 & 0.100 & 0.920 \\
\hline IPP & 1.246 & 0.215 & 0.924 & 0.357 & 0.956 & 0.340 \\
\hline PUA & 2.172 & $0.032 *$ & 1.451 & 0.149 & 3.549 & $<0.00 I^{*}$ \\
\hline
\end{tabular}

Note: *Multivariate linear regression analysis.

Abbreviations: IPSS, International Prostate Symptom Score; BMI, body mass index; TPV, total prostate volume; IPP, intravesical prostate protrusion; PUA, prostatic urethral angle.

and three items for storage symptoms). Each of them is rated from 0 (not at all) to 5 (almost all the time). The total score is the sum of the seven items, and thus has a range from 0 to 35 . The greater the score, the more severe the symptoms are. ${ }^{14}$ To evaluate the anatomical structure of the prostate, TRUS is a relatively accurate study that can be carried out at an outpatient clinic. ${ }^{15}$ When performing a TRUS examination, the prostatic urethra can be seen clearly on the sagittal view. It runs through the prostate from the base to the apex, making an acute angle at the proximal part of the verumontanum. This is defined as the PUA. ${ }^{16}$ An increased PUA may be the result of a high bladder neck, which is suspected as a clinically significant causal factor of male LUTS. ${ }^{7}$

In our study, the PUA had a significant association with IPSS and $\mathrm{Q}_{\max }$, as shown in Tables 2 and 3. Figure 2 demonstrates that the greater the degree of the PUA, the more severe the LUTS and lower the $\mathrm{Q}_{\max }$ will be. This clinical finding is compatible with previous literature. $\mathrm{Ku}$ et al found that the PUA correlated with the bladder outlet-obstruction index. In other words, as the PUA increases, the severity of bladder outlet obstruction increases. ${ }^{17}$ Bang et al revealed that PUA was significantly associated with $\mathrm{Q}_{\max }$ and IPSS in men with LUTS. ${ }^{18}$

Another possible prostatic parameter that has an association with voiding function is IPP. Chia et al suggested that IPP causes a "ball-valve" type of obstruction. It disrupts the

Table 5 Relationship between $\mathrm{Q}_{\max }$ change and prostatic parameters after tamsulosin treatment

\begin{tabular}{lll}
\hline Variable & t-ratio & $P$-value \\
\hline Age & 0.066 & 0.947 \\
BMI & 0.804 & 0.422 \\
TPV & 0.352 & 0.725 \\
IPP & 0.614 & 0.540 \\
PUA & 5.775 & $<0.00 I^{*}$ \\
\hline
\end{tabular}

Note: *Multivariate linear regression analysis.

Abbreviations: $\mathrm{Q}_{\max }$, peak flow rate; $\mathrm{BMI}$, body mass index; TPV, total prostate volume; IPP, intravesical prostate protrusion; PUA, prostatic urethral angle. 

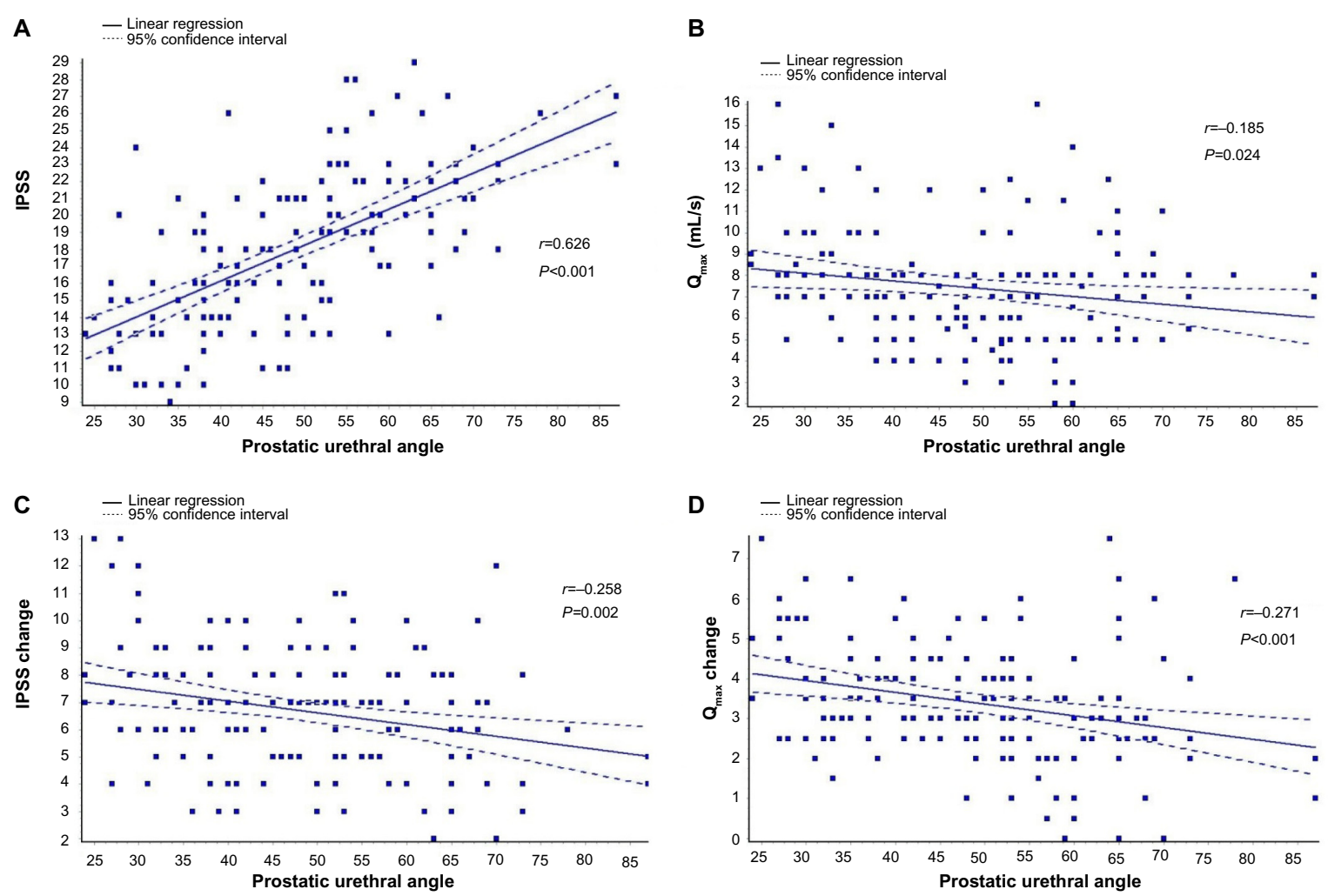

Figure 2 Correlation between prostatic urethral angle and (A) IPSS, (B) $Q_{\max }$ (C) $\triangle I P S S$, and (D) $\Delta Q_{\max }$ Abbreviations: IPSS, International Prostate Symptom Score; $\mathrm{Q}_{\max }$, peak flow rate.

funneling effect of the bladder neck, causing dyskinesia of the bladder during voiding. ${ }^{19}$ However, our study shows that IPP is a parameter that correlates with neither IPSS nor $\mathrm{Q}_{\max }$. The possible reason might be that the mean IPP of our patients was only $5.67 \mathrm{~mm}$, while Keqin et al suggested using an IPP threshold of $10 \mathrm{~mm}$ to classify bladder outlet-obstruction patients better. ${ }^{20}$ Therefore, most of our patients' IPPs were too small to reveal the correlation between IPSS and $\mathrm{Q}_{\max }$.

Another aim of our study was to determine whether the PUA had a correlation with the treatment efficacy of $\alpha$-blockers in men with LUTS. $\alpha$-Blockers help to treat $\mathrm{BPH}$ by relaxing smooth-muscle tissue in the prostate and the bladder neck. This allows urine to flow out of the bladder more easily. ${ }^{21}$ The reason we chose tamsulosin to treat our patients was that it is a highly selective $\alpha_{1 \mathrm{~A}}$-subtype antagonist. ${ }^{22}$ It is safe and effective in the long-term treatment of BPH. The changes from baseline for LUTS and $\mathrm{Q}_{\max }$ were statistically significant. Moreover, tamsulosin is well tolerated by patients, and the incidence of adverse events does not increase over time. ${ }^{22}$ However, it is still very hard to explain why some patients experience good treatment results after taking $\alpha$-blockers while some do not. The results of our study may provide a good interpretation. As shown in Tables 4 and 5, PUA was the only parameter that had a correlation with $\Delta \mathrm{IPSS}$ and $\Delta \mathrm{Q}_{\max }$ after medication. However, age, BMI, prostate volume, and IPP were not associated with treatment efficacy. Figure $2 \mathrm{C}$ and D illustrate that $\triangle \mathrm{IPSS}$ and the $\Delta \mathrm{Q}_{\max }$ were inversely associated with the PUA. Therefore, our study findings can confirm our hypothesis that as the PUA increases, the treatment efficacy of tamsulosin decreases. Therefore, the PUA measured by TRUS might be a good predictor of the treatment efficacy of $\alpha$-blockers in male LUTS.

In this study, the starting dose was $0.2 \mathrm{mg}$ per day. The effect of this dosage for some patients was not good enough, but with increased dosage, switching to another $\alpha$-blocker, or performing TUR-P, the patients' symptoms improved. In our data, the average PUA was $48.32^{\circ}$. By doing further analysis, we discovered that for patients with a PUA $<48.32^{\circ}$, none required TUR-P within 1 year. On the contrary, of the patients with a PUA $>48.32^{\circ}$, ten requested TUR-P within 3 months. Despite having their medication changed or dosage increased, 19 patients finally received TUR-P within 1 year due to lack of effects of the medicine. The results of our study possibly show that patients with a higher PUA stand a greater chance of requiring TUR-P within 1 year. On the other hand, for 
patients with a PUA $<48.32^{\circ}$, medication worked on the majority and none underwent surgery within 1 year, according to the results of our study.

There are still some faults in our study that are worth mentioning. First, flow pressure measured by urodynamic investigations is a more accurate method to evaluate bladderoutlet obstruction. ${ }^{23}$ However, we used only uroflowmetry and bladder scans rather than urodynamic study to evaluate patients' voiding function. As a result, the accuracy might be questionable. Second, the PUA is measured at resting status, but not at voiding status. In fact, the prostatic urethral anatomy can be altered during micturition, and the PUA may not reflect the anatomy of the prostatic urethra during voiding. ${ }^{24}$ Another flaw of this work was the lack of a placebo arm and the fact that it was a pilot study performed at only one center. Also, the dosage of $0.4 \mathrm{mg}$ of tamsulosin should be tested to investigate if the association between PUA, $Q_{\max }$, and IPSS variation is stronger. Last but not least, we followed our patients for only 3 months. The relationship between the PUA and the long-term treatment result of tamsulosin on male LUTS should be clarified by further study in the future.

\section{Conclusion}

Like previous studies in the literature, the results of ours revealed that the PUA is significantly associated with $\mathrm{Q}_{\max }$ and IPSS in men with LUTS. Our study also suggests that the PUA is inversely correlated with the $\Delta \mathrm{Q}_{\max }$ and the $\Delta$ IPSS after tamsulosin treatment. PUA might be a predictor of the treatment efficacy of $\alpha$-blockers in male patients with LUTS.

\section{Disclosure}

The authors report no conflicts of interest in this work.

\section{References}

1. Verhamme KM, Dieleman JP, Bleumink GS, et al. Incidence and prevalence of lower urinary tract symptoms suggestive of benign prostatic hyperplasia in primary care - the Triumph project. Eur Urol. 2002;42:323-328.

2. Bushman W. Etiology, epidemiology, and natural history of benign prostatic hyperplasia. Urol Clin North Am. 2009;36:403-415.

3. Sciarra A, D'Eramo G, Casale P, et al. Relationship among symptom score, prostate volume, and urinary flow rates in 543 patients with and without benign prostatic hyperplasia. Prostate. 1998;34:121-128.

4. Yuen JS, Ngiap JT, Cheng CW, Foo KT. Effects of bladder volume on transabdominal ultrasound measurements of intravesical prostatic protrusion and volume. Int J Urol. 2002;9:225-229.
5. Kaplan SA, Te AE, Pressler LB, Olsson CA. Transition zone index as a method of assessing benign prostatic hyperplasia: correlation with symptoms, urine flow and detrusor pressure. J Urol. 1995;154: 1764-1769.

6. Keqin Z, Zhishun X, Jing Z, Yoo TK. Clinical significance of intravesical prostatic protrusion in patients with benign prostatic enlargement. Urology. 2007;70:1096-1099.

7. Cho KS, Kim JH, Kim DJ, Choi YD, Kim JH, Hong SJ. Relationship between prostatic urethral angle and urinary flow rate: its implication in benign prostatic hyperplasia pathogenesis. Urology. 2008;71:858-862.

8. Cho KS, Kim J, Choi YD, Kim JH, Hong SJ. The overlooked cause of benign prostatic hyperplasia: prostatic urethral angulation. Med Hypotheses. 2008;70:532-535.

9. White FM. Viscous Fluid Flow. Boston: McGraw-Hill Higher Education; 2006.

10. Nose H, Foo KT, Lim KB, Yokoyama T, Ozawa H, Kumon H. Accuracy of two noninvasive methods of diagnosing bladder outlet obstruction using ultrasonography: intravesical prostatic protrusion and velocityflow video urodynamics. Urology. 2005;65:493-497.

11. Oelke M, Bachmann A, Descazeaud A, et al. EAU guidelines on the treatment and follow-up of non-neurogenic male lower urinary tract symptoms including benign prostatic obstruction. Eur Urol. 2013;64: 118-140.

12. Berry SJ, Coffey DS, Walsh PC, Ewing LL. The development of human benign prostatic hyperplasia with age. J Urol. 1984;132:474-479.

13. Geller J. Overview of benign prostatic hypertrophy. Urology. 1989;34:57-63.

14. Madersbacher S, Alivizatos G, Nordling J, Sanz CR, Emberton M, de la Rosette JJ. EAU 2004 guidelines on assessment, therapy and follow-up of men with lower urinary tract symptoms suggestive of benign prostatic obstruction (BPH guidelines). Eur Urol. 2004;46:547-554.

15. Terris MK, Stamey TA. Determination of prostate volume by transrectal ultrasound. J Urol. 1991;145:984-987.

16. McNeal JE. The prostate and prostatic urethra: a morphologic synthesis. J Urol. 1972;107:1008-1016.

17. Ku JH, Ko DW, Cho JY, Oh SJ. Correlation between prostatic urethral angle and bladder outlet obstruction index in patients with lower urinary tract symptoms. Urology. 2010;75:1467-1471.

18. Bang WJ, Kim HW, Lee JY, et al. Prostatic urethral angulation associated with urinary flow rate and urinary symptom scores in men with lower urinary tract symptoms. Urology. 2012;80:1333-1337.

19. Chia SJ, Heng CT, Chan SP, Foo KT. Correlation of intravesical prostatic protrusion with bladder outlet obstruction. BJU Int. 2003;91:371-374.

20. Keqin Z, Zhishun X, Jing Z, Haixin W, Dongqing Z, Benkang S. Clinical significance of intravesical prostatic protrusion in patients with benign prostatic enlargement. Urology. 2007;70:1096-1099.

21. Lepor H. Alpha blockers for the treatment of benign prostatic hyperplasia. Rev Urol. 2007;9:181-190.

22. Narayan P, Lepor H. Long-term, open-label, phase III multicenter study of tamsulosin in benign prostatic hyperplasia. Urology. 2001;57: 466-470.

23. Heinzelbecker J, Michel MS. Bladder outflow obstruction, urodynamic studies and BPH. In: Bachmann A, de la Rosette J, editors. Benign Prostatic Hyperplasia and Lower Urinary Tract Symptoms in Men. Oxford: Oxford University Press; 2011:43-48.

24. Ku JH, Ko DW, Cho JY, Oh SJ. Correlation between prostatic urethral angle and bladder outlet obstruction index in patients with lower urinary tract symptoms. Urology. 2010;75:1467-1471. 


\section{Publish your work in this journal}

Drug Design, Development and Therapy is an international, peerreviewed open-access journal that spans the spectrum of drug design and development through to clinical applications. Clinical outcomes, patient safety, and programs for the development and effective, safe, and sustained use of medicines are a feature of the journal, which has also been accepted for indexing on PubMed Central. The manuscript management system is completely online and includes a very quick and fair peer-review system, which is all easy to use. Visit $\mathrm{http}: / / \mathrm{www}$.dovepress.com/testimonials.php to read real quotes from published authors.

Submit your manuscript here: http://www.dovepress.com/drug-design-development-and-therapy-journal 